\title{
Cisplatin enhances the efficacy of 5-aminolevulinic acid-mediated photodynamic therapy in human head and neck squamous cell carcinoma
}

\author{
Jin-Chul Ahn ${ }^{1}$, Raktim Biswas ${ }^{1}$, Arindam Mondal ${ }^{1}$, Young-Ki Lee ${ }^{2}$ and Phil-Sang Chung ${ }^{1,3}$ \\ ${ }^{1}$ Medical Laser Research Center, College of Medicine, Dankook University, Cheonan, Chungnam, Korea \\ ${ }^{2}$ Department of Public Health, Graduate School of Public Health and Social Welfare, Dankook University, Cheonan, \\ Chungnam, Korea \\ ${ }^{3}$ Department of Otolaryngology-Head and Neck Surgery, College of Medicine, Dankook University, Cheonan, Korea
}

\begin{abstract}
Photodynamic therapy (PDT) has become a promising option for the treatment of head and neck, and other forms of cancer. 5-Aminolevulinic acid (ALA) is one of the popular photosensitizers used in PDT. It is a heme precursor and is converted to a photosensitizer protoporphyrin IX. In this present study, the combination of anticancer drug cisplatin (CDDP)- and ALA-mediated PDT was used to study the cytotoxicity in vitro as well as in vivo. Human head and neck cancer cells AMC-HN3 were treated with cisplatin- and ALA-mediated PDT individually, and also in combination. Several approaches like confocal microscopic study, cytotoxicity assay, etc have been performed to study the intracellular accumulation of protophorphyrin IX in cells and its effectiveness in PDT, when treated in combination with chemotherapy drug, cisplatin (CDDP). The combination of treatments efficacy was also studied in tumor xenograft model. Compared to the individual treatments, combination of CDDP and PDT was found to be more cytotoxic in AMC-HN3, and also more effective in reducing the tumor volume in mice xenograft. Thus with the combined therapy, not only the efficacy of treatment can be enhanced, but the doses of the drugs can also be lowered. This in turn can reduce the side effects of the chemotherapy drugs. Therefore, this study may lead to a potential drug-PDT combination that may be a useful treatment modality for human head and neck cancer.
\end{abstract}

Key words: Cisplatin — ALA - Photodynamic therapy - Head and neck cancer

\begin{abstract}
Abbrevitions: ALA, 5-aminolevulinic acid; CDDP, cis-diamino-dichloro-platin (cisplatin); DMEM, Dulbecco's modified Eagle medium; DMSO, dimethyl sulfoxide; FBS, foetal bovine serum; PDT, photodynamic therapy; PpIX, protoporphyrin IX.
\end{abstract}

\section{Introduction}

Photodynamic therapy (PDT) is used to treat several types of cancer by the administration of a light absorbing chemical,

Correspondence to: Phil-Sang Chung, Department of Otolaryngology-Head and Neck Surgery, Medical Laser Research Center, College of Medicine, Dankook University, 29-1, Anseo-dong, Cheonan, Chungnam, 330-714, Korea

E-mail: pschung@dankook.ac.kr

Young-Ki Lee, Department of Public Health, Graduate School of Public Health and Social Welfare, Dankook University, 29-1, Anseo-dong, Cheonan, Chungnam, 330-714, Korea E-mail: pp99pp@dankook.ac.kr known as photosensitizer and light of a specific wavelength. The photosensitizer is activated by absorbing light and produces singlet oxygen, causing damage to the tumor cells (Dougherty et al. 1998). The mechanism of the anticancer effect of photodynamic therapy has been studied where generation of singlet oxygen and free radicals were reported to promote the secondary necrosis of the cancer cells (Henderson and Dougherty 1992). Hematoporphyrin photosensitizers are one of the commonly used photosensitizers in PDT (PujolLereis et al. 2010). But the main disadvantage of currently used hematoporphyrin photosensitizer in PDT is its long-lasting skin phototoxicity (Wolford et al. 1995). Therefore, several studies are being performed to reduce this skin phototoxicity. Recently, 5-aminolevulinic acid (ALA) is becoming popular 
in PDT to treat various diseases (Kennedy et al. 1992). ALA is converted to photosensitizer, protoporphyrin IX (PpIX) in the biosynthetic pathway of heme (Heinemann et al. 2008). After exogenous administration of ALA, PpIX accumulates within cells, resulting in comparatively low activity of ferrochelatase, the enzyme responsible for the conversion of PpIX to heme. The useful aspect of ALA-PDT is that protoporphyrins IX along with other intermediates are rapidly eliminated from the body and hence the risk of prolonged skin photosensitivity is limited to one to two days. This may be one of the important reasons for choosing ALA as an efficient photosentizer in PDT (Kennedy et al. 1990, 1992). Several studies have been reported to use ALA as a photosensitizer in PDT to treat several cancers like gastrointestinal tract, skin, lung, bladder, oral cancer (Karmakar et al. 2007; Bourré et al. 2008; Gui et al. 2012).

On the other hand, cisplatin has been used as an anticancer drug for a long time (Go and Ajei 1999; Geisler et al. 2012). Cisplatin alone or in combination with other treatment modalities showed effectiveness in the treatment of malignant tumors of the head and neck (Uehara et al. 2006; Mao et al. 2009; de Carvalho Maroni et al. 2012; Minami et al. 2012). However, the administration of cisplatin alone has some limitations of severe side effects (Florea and Büsselberg 2011). Cisplatin has been reported to have adverse effects like renal toxicity, ototoxicity, etc (Ravi et al. 1995; Zhang et al. 2007; Yao et al. 2007). Combination of cisplatin with other conventional treatment modalities has been studied to reduce its side effects with the enhanced efficacy (Azmi et al. 2010, Ehrlich et al. 2010; Okusaka et al. 2010, Segawa et al. 2010).

In the present study, the efficacy of cisplatin (CDDP), ALA-PDT and CDDP+ALA-PDT combination therapy was compared to find out whether an enhanced efficacy can be obtained on human head and neck cancer cells, AMC$\mathrm{HN} 3$. By this combination treatment with cisplatin and ALA-PDT, not only the efficacy of PDT can be enhanced but the adverse side effects of chemotherapy drugs can also be reduced by reducing the doses of individual drugs. Therefore, the combination CDDP and ALA-PDT can lead to a promising mode of treatment of head and neck cancer with an enhanced efficacy and lower side effects as well.

\section{Materials and Methods}

\section{Chemicals}

The photosensitiser ALA (5-aminolevulinic acid), was purchased from Sigma-Aldrich, Korea. A stock solution was made in DPBS and kept in aluminium foil at $-20^{\circ} \mathrm{C}$. Anticancer drug cisplatin (CDDP: cis-diamino-dichloro-platin) purchased from United Pharm. Korea and a stock solution was prepared by diluting it in dimethyl sulphoxide (DMSO). For cell culture, all medium supplements, that is DMEM, foetal bovine serum (FBS) and antibiotics were supplied by Hyclone (South Logan, UT, USA). 3-[4,5-Dimethylthiazol-2yl]-2,5-diphenyl-tetrazolium bromide (MTT), DMSO were purchased from Sigma (St. Louis, MO, USA).

\section{Cell culture}

The human head and neck squamous carcinoma cell line AMC-HN3 were grown in DMEM culture medium containing $10 \%$ FBS and $1 \%$ antibiotic-antimycotic solution in a cell culture flask (Nunc, Denmark). The cells were maintained at $37^{\circ} \mathrm{C}$ and $5 \% \mathrm{CO}_{2}$ in a humidified atmosphere. The morphology of the cells was observed by inverted microscope (Olympus CK40, Japan).

\section{Accumulation of intracellular photosensitizer}

To check the accumulation of photosensitizer into cells, $10^{5}$ cells/ml of AMC-HN3 cells, in exponential growth phase, were seeded in a 6 well plate and incubated at $37^{\circ} \mathrm{C}$ and $5 \% \mathrm{CO}_{2}$ incubator for $24 \mathrm{~h}$ and were allowed to adhere to the surface of the culture plate. After $24 \mathrm{~h}$ of incubation, the culture media was replaced with the fresh serum free medium containing $1 \mathrm{mM}$ ALA. Formation of PpIX and its accumulation in the cells were observed by the confocal laser scanning microscope after $0,3,6$ and $9 \mathrm{~h}$ of treatment. The images taken by confocal microscope were analyzed by Image J software (National Institutes of Health) to quantify the fluorescence of the cells.

\section{CDDP monotherapy}

To measure the cell cytotoxicity by CDDP monotherapy, $100 \mu \mathrm{g} / \mathrm{ml}$ CDDP was filtered with sterile $0.2 \mu \mathrm{m}$ syringe filter (Gelman, USA) and diluted with $100 \mu \mathrm{l}, \mathrm{pH} 7.3$ in DPBS (Hyclone, USA) and the cells were treated with different concentrations from $0-25 \mu \mathrm{g} / \mathrm{ml}$.

\section{ALA-PDT monotherapy}

In a 96 well plate, cells were treated with ALA starting from $0-200 \mu \mathrm{g} / \mathrm{ml}$ in a serum-free medium and incubated at $37^{\circ} \mathrm{C}$ for $24 \mathrm{~h}$. After $24 \mathrm{~h}$ of incubations, the culture medium were replaced with the fresh one and the laser irradiation was performed by using a laser of $632 \mathrm{~nm}$ for $15 \mathrm{~min}$ to obtain an energy of $6.0 \mathrm{~J} / \mathrm{cm}^{2}$ using a reflector plate $10 \mathrm{~cm}$ above the diffuser tip.

\section{$C D D P+A L A-P D T$ combination therapy}

The cells were treated with $6.25 \mu \mathrm{g} / \mathrm{ml}$ CDDP and ALA $(25 \mu \mathrm{g} / \mathrm{ml}$ and $50 \mu \mathrm{g} / \mathrm{ml})$ in serum-free medium, and incubated for $24 \mathrm{~h}$. After incubation, a laser of $6.0 \mathrm{~J} / \mathrm{cm}^{2}$ was irradiated using a reflector plate above the $10 \mathrm{~cm}$ diffuser tip. 


\section{Cell cytotoxicity test}

MTT assay methods (Scudiero DA et al. 1988) were used to evaluate the effect of CDDP, ALA-PDT and CDDP+ALAPDT in combination against AMC-HN3 cells. Briefly, after the treatment with CDDP and ALA-PDT singly or in combination for $24 \mathrm{~h}, 50 \mu \mathrm{l}$ of MTT solution $(2 \mathrm{mg} / \mathrm{ml})$ was added to each well and incubated for 4 hours. After incubation, the medium of each well were removed and $150 \mu \mathrm{l}$ of DMSO was added to dissolve the violet-blue crystals of metabolized products. The absorbances of each well were measured at 540 nm using Asys UVM340 microplate Reader, Biochrom. The percentage of cell viability was calculated using the following equation:

Cell viability $(\%)=\frac{\text { Mean optical density in test well }}{\text { Mean optical density in control well }} \times 100$

\section{Cell morphology study by optical microscopy}

The concurrent appearance of the cells before and after treatment of CDDP and ALA-PDT were observed through the inverted microscope (Olympus CK40, Japan). The morphology of the cells of control and treated groups were observed and the photographs were taken. Cell morphology of control and treated groups were also compared.

\section{Tumour xenograft}

AMC-HN3 cell lines were maintained at $37^{\circ} \mathrm{C}$ temperature and $5 \% \mathrm{CO}_{2}$ in an incubator for a exponential growth. Cells were then harvested by $0.25 \%$ trypsin-EDTA and a suspension of cell with a concentration of $10^{8}$ cells $/ \mathrm{ml}$ in a medium was prepared. The cell suspension was injected subcutaneously into the back of 6 week old BALB/c/nu/nu female mice with a 30 gauge $(\mathrm{G}) 0.1 \mathrm{ml}$ insulin syringe. The formation of tumors was observed from 1 week to 4 weeks and the tumor sizes were measured once a week. The animal studies were performed in accordance with the experimental protocols of the animal ethics committee of Dankook University.

\section{Photodynamic therapy of tumors}

When the tumor reaches about $100-300 \mathrm{~mm}^{3}$ in size, the experimental tumor xenograft mice $(n=60)$ were divided into five experimental groups as follows:

- Laser group $(n=10)$ : tumors irradiated from the four directions by $632 \mathrm{~nm}$ diode laser $\left(132 \mathrm{~J} / \mathrm{cm}^{2}, 400 \mathrm{~mW}\right)$

- ALA group $(n=10)$ : ALA-administered group

- CDDP group $(n=10): 2 \mathrm{mg} / \mathrm{kg}$ of CDDP-administered group

- ALA-PDT group ( $n=15)$ : (ALA-PDT groups in laboratory mice), $375 \mathrm{mg} / \mathrm{kg}$ of ALA were injected intra- peritoneally and after $6 \mathrm{~h}$, laser was administered for PDT

- CDDP+ALA-PDT group $(n=15)$ : ALA-PDT and CDDP combined treatment group.

The cells without any treatment (neither with CDDP nor with ALA-PDT) served as a control group.

\section{Determination of the antitumor effect}

To study the antitumor effect, tumor volume was measured twice in a week after treating the mice as mention above. Tumor volume of each mouse from each group was measured with calipers and was calculated using the following formula:

$\mathrm{V}=(4 / 3 \times \mathrm{A} \times \mathrm{B} \times \mathrm{C}) \times 1 / 2$

where $\mathrm{V}$ is volume, $\mathrm{A}$ is longest diameter, $\mathrm{B}$ is shortest diameter and $\mathrm{C}$ is diameter perpendicular to $\mathrm{A}$ and $\mathrm{B}$.

\section{Hematoxylin and eosin staining}

Frozen tissue sections on glass slides were fixed in acetone (Sigma-Aldrich) for $10 \mathrm{~min}$. The tissue sections were allowed to dry for $10 \mathrm{~min}$ and then immediately stained with Mayer hematoxylin (Sigma-Aldrich) for another $10 \mathrm{~min}$. Afterward, the slides were rinsed in tap water and then stained with eosin (Surgipath, Richmond, IL, USA) for $10 \mathrm{~s}$. The slides were then dehydrated in $95 \%$ and $100 \%$ ethanol in succession for $10 \mathrm{~s}$ followed by $30 \mathrm{~s}$ incubation in xylene (Sigma-Aldrich). Finally, the slides were mounted on glass coverslips, sealed and analyzed under the microscope. Stained tumor sections were visualized at $100 \times$ magnification and images were taken for further study.

\section{Statistical analysis}

Results are expressed as the mean \pm standard deviation (SD). The significance of differences was evaluated by oneway analysis of variance (ANOVA) followed by the least significant difference procedure (LSD). Differences were considered statistically significant at $p<0.05$.

\section{Results}

Observed the accumulation of intracellular photosensitizer

The intracellular accumulation of PpIX was observed by confocal laser scanning microscopy according to incubation time 0, 3, 6 and 9 hours after ALA application. The fluorescence intensities of the cells were measured by Image J software. The changes in average intensities of the each well with incubation time were expressed in a histogram. From the histogram it can be stated that the PpIX fluorescence was saturated after $6 \mathrm{~h}$ of ALA application to AMC-HN3 cell (Fig. 1). 

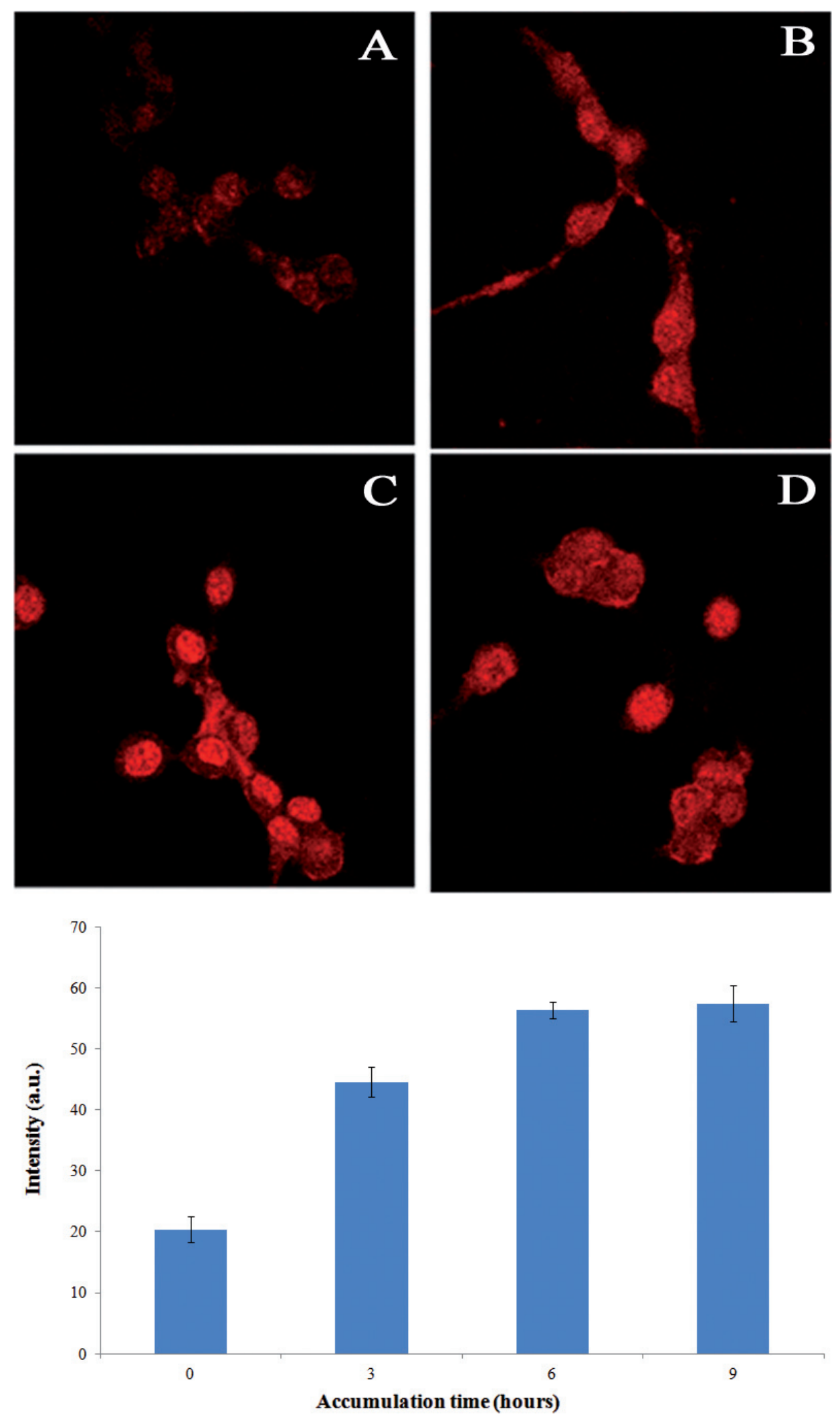

Figure 1. Intracellular accumulation of PpIX according to incubation time with ALA - 0 h (A), $3 \mathrm{~h}(\mathbf{B}), 6 \mathrm{~h}(\mathrm{C})$, and $9 \mathrm{~h}$ (D) after ALA application. Graph shows that the fluorescence of PpIX was saturated at $6 \mathrm{~h}$ after the ALA application to AMC-HN3 cell. 


\section{Optical microscopy}

The morphologies of the cells treated with PDT only and CDDP+ PDT combination were observed through inverted microscope and compared with the control. In the control group, most of the cells were attached to the bottom of the culture flask and were in growing condition. In ALA-PDT group, some of the cells were eliminated from the bottom of the cell culture flasks and in CDDP+ALA-PDT group a large number of cells was eliminated from the bottom of the culture flask. The morphology of the treated cells in combination group was also changed compared to the control cell. In combination group, most of the cells were round shaped. Changes in the cell membrane can also be observed (Fig. 2).

\section{Cytotoxicity study by MTT assay}

The viability of cell was measured by MTT assay and the percentage of cell viability was calculated for different concentrations of CDDP and also for different time interval from 3 to $48 \mathrm{~h}$. From $1.56 \mu \mathrm{g} / \mathrm{ml}$ or higher concentrations of CDDP, overall cell viability was significantly lowered. From the MTT assay, it can be stated that the viability of AMC$\mathrm{HN} 3$ cell was decreased with the increasing concentration of CDDP as well as the incubation time (Fig. 3A).

From the concentration of $12.5 \mu \mathrm{g} / \mathrm{ml}$, ALA begun to show a significant difference in cell viability compared to the control. Viability of the cells was decreased significantly with the increasing concentration of ALA for PDT. Most of the cells were dead for the ALA concentration of $100 \mu \mathrm{g} / \mathrm{ml}$ and above (Fig. 3B).

AMC-HN3 cells were treated with CDDP and ALA-PDT individually as well as in combination. Viability of cell was decreased when the cells were treated with $6.25 \mu \mathrm{g} / \mathrm{ml}$ of CDDP and incubated for $24 \mathrm{~h}$. Cell viability was also decreased for ALA-PDT at concentrations of $25 \mu \mathrm{g} / \mathrm{ml}$ and
$50 \mu \mathrm{g} / \mathrm{ml}$ of ALA. However, the cytotoxic effect of ALA-PDT was much higher for higher concentration of ALA. But for the cells treated with combination of $6.25 \mu \mathrm{g} / \mathrm{ml}$ of CDDP and different concentrations of ALA in PDT, the cell viabilities were dramatically decreased compared to the individual treatments of CDDP and ALA-PDT respectively. Moreover, most of the cells were dead for the highest concentration of ALA $(50 \mu \mathrm{g} / \mathrm{ml})$ for PDT in combination with CDDP (Fig. 3C).

\section{The photodynamic therapy of xenograft tumors}

After 4 weeks of treatment, Laser group, ALA group and CDDP group showed an increase in the size of the tumor in all cases. In ALA-PDT group, the tumor was not healed in 3 mice (20\%), in 8 cases (53\%) tumor was cured and 4 cases showed tumor recurrence $(27 \%)$. On the other hand, in CDDP+ALA-PDT group, complete tumor remission was occurred in 12 cases (80\%) and one case showed tumor recurrence (7\%) (Fig. 4).

After 28 days of PDT treatments, size of the tumor was compared to that of prior to treatment. For Laser group, 2 weeks after the laser treatment the size of the tumor was increased compared to that of before treatment from $532 \pm$ $51 \mathrm{~mm}^{3}$ to $842 \pm 167 \mathrm{~mm}^{3}$ whereas 4 weeks after it was observed to be increased steadily to $1258 \pm 370 \mathrm{~mm}^{3}$. Two weeks after the administration of ALA only (ALA group), the size of the tumor was increased from $510 \pm 12 \mathrm{~mm}^{3}$ to $860 \pm 8.5 \mathrm{~mm}^{3}$ and again after four weeks, it was increased steadily to $1344 \pm 252 \mathrm{~mm}^{3}$. Two weeks after administration of CDDP only (CDDP group), the size of the tumor was increased from $396 \pm 102 \mathrm{~mm}^{3}$ to $574 \pm 104 \mathrm{~mm}^{3}$ and again after four weeks it was increased steadily to $1125 \pm$ $94 \mathrm{~mm}^{3}$. On the other hand, two weeks after administration of ALA-PDT (ALA-PDT group), the size of the tumor was decreased from $512 \pm 38 \mathrm{~mm}^{3}$ to $68 \pm 2.5 \mathrm{~mm}^{3}$ but for four weeks, it was slightly increased to $195 \pm 129 \mathrm{~mm}^{3}$. How-
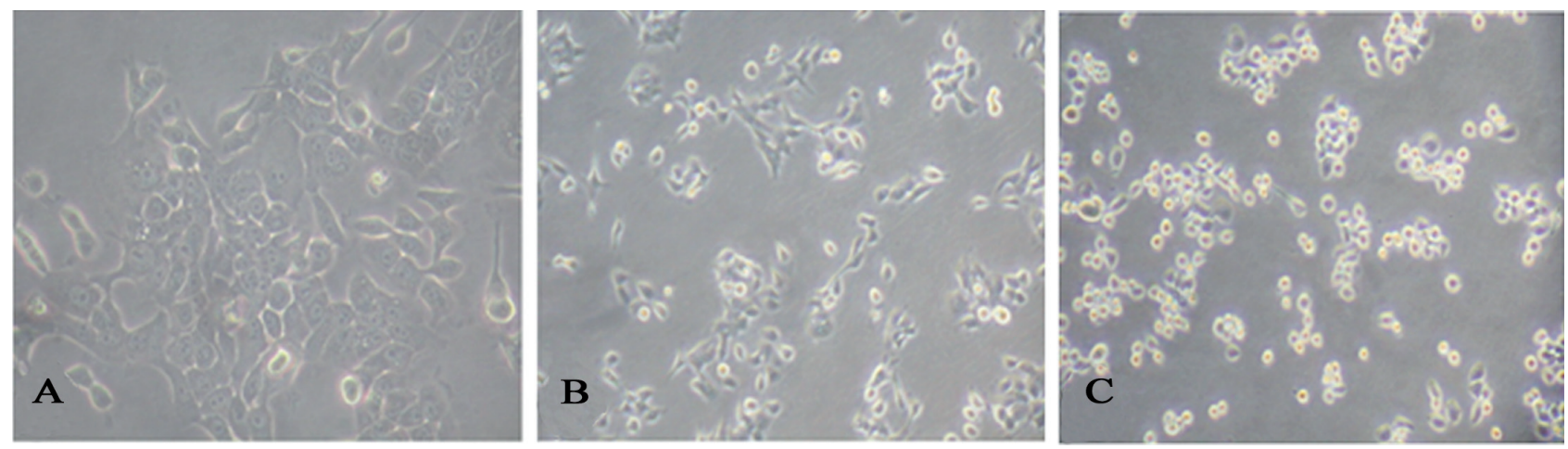

Figure 2. Microscopic findings of AMC-HN3 cells in culture flask (magnification $\times 200$ ) before and after treatment. A. Normal cells without any treatment. B. Cells treated with ALA-PDT only. C. AMC-HN3 cells treated with CDDP+PDT in combination. 


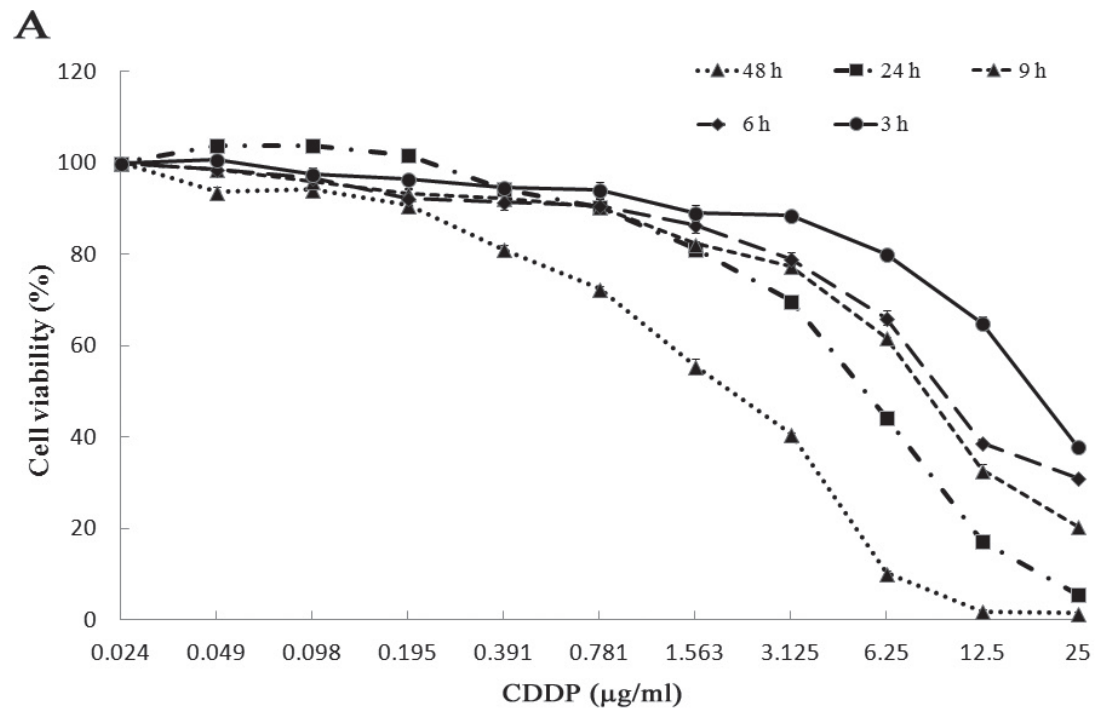

B

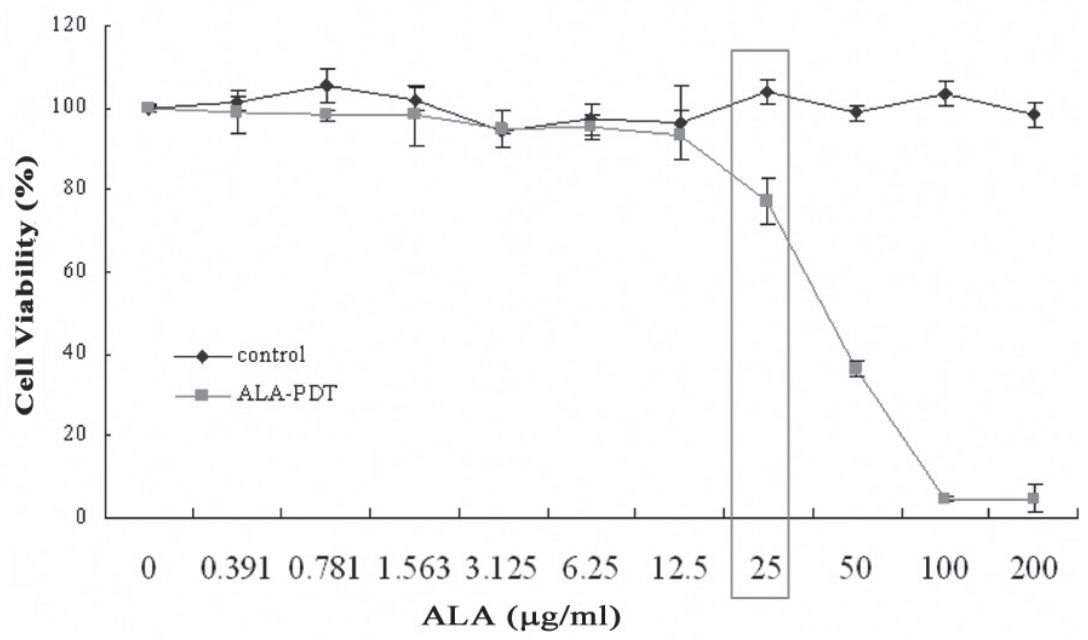

C

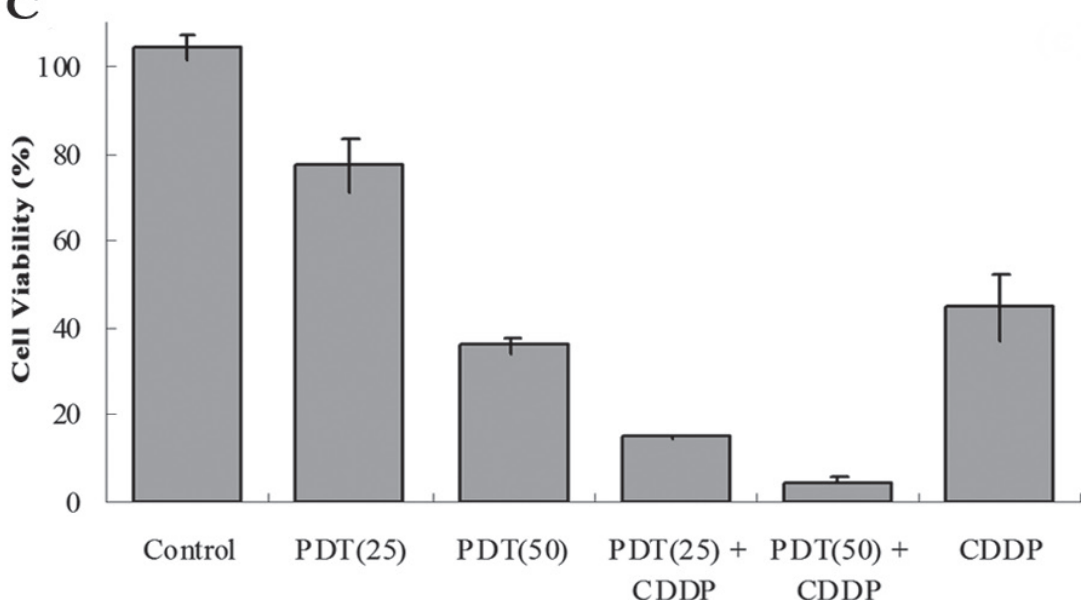

Figure 3. A. Cell viability of AMC-HN3 cell by incubation time with various concentrations of cisplatin. B. Effect of various concentration of ALA-based PDT on AMC-HN3 cell viability. C. Effect of ALA-PDT+CDDP combination therapy on AMC-HN3 cells. Control, normal cells with no treatment; PDT(25), PDT with $25 \mu \mathrm{g} / \mathrm{ml}$ of ALA; PDT(50), PDT with $50 \mu \mathrm{g} / \mathrm{ml}$ of ALA; CDDP, $6.25 \mu \mathrm{g} / \mathrm{ml}$ of CDDP. 
ever, for administration of ALA-PDT and CDDP combined therapy (CDDP+ALA-PDT group), the size of the tumor was decreased from $445 \pm 29 \mathrm{~mm}^{3}$ to $32 \pm 40 \mathrm{~mm}^{3}$ after two weeks and after four weeks it was again decreased slightly to $27 \pm 85 \mathrm{~mm}^{3}$ (Fig. 5A).

Hematoxylin-eosin staining of tumor xenograft was performed to confirm the therapeutic effect of the combination treatment with CDDP and ALA-PDT. Throughout observations were done for the control and combination treatment groups for $24 \mathrm{~h}$ before treatment; $24 \mathrm{~h}$ and $48 \mathrm{~h}$ after the treatment. The tumor necrosis and lymphocyte infiltration and a wide range of coagulative necrosis of the tumor were also observed for $48 \mathrm{~h}$ of post treatment with combination therapy (Fig. 5B).

\section{Discussion}

The main advantage of using ALA in PDT is that it has less side effect compared to other photosensitizers (Kennedy and Pottier 1992). Generally, most of the currently used photosensitizers are spread all over the body after administration. This may cause toxicity in different organs during PDT. However, ALA is mainly accumulated in mucous membrane, therefore a relatively lesser risk of side effects are expected. In addition, ALA can also be administered orally unlike the other photosensitizers, which are commonly administered by injection (Kennedy et al. 1990, Sharman et al. 1999).

The amount of generated PpIX in cultured cell lines can be observed by measuring the fluorescence of PpIX after ALA administration. Generally maximum fluorescence of PpIX can be observed at 1 to 6 hours after the administration of ALA (Regula et al. 1995). The accumulated PpIX is responsible for the release of serum into the medium. So the media should be serum free in the experimental groups (Bourré et al. 2008). Thus serum free media was used for our present in vitro study. A chemotherapy drug cisplatin was used in combination to increase the efficiency of killing tumor cells by ALA-PDT. In this combination therapy, the lowest concentration of CDDP was used $6.25 \mu \mathrm{g} / \mathrm{ml}$ which was close to the IC50 value after $24 \mathrm{~h}$ of incubation with the drug. On the
A
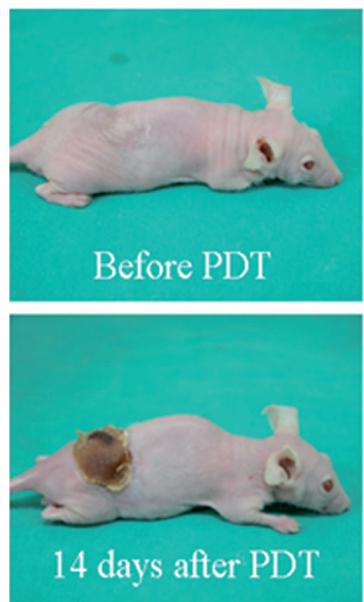

B
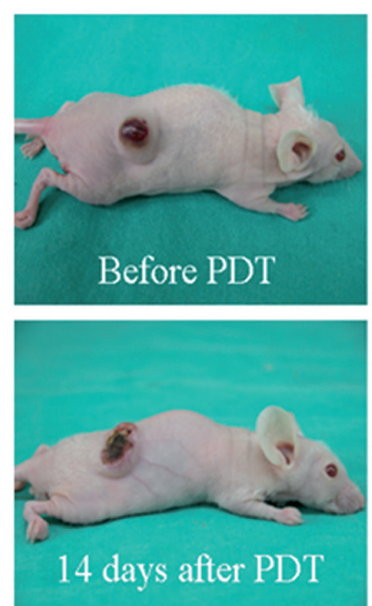
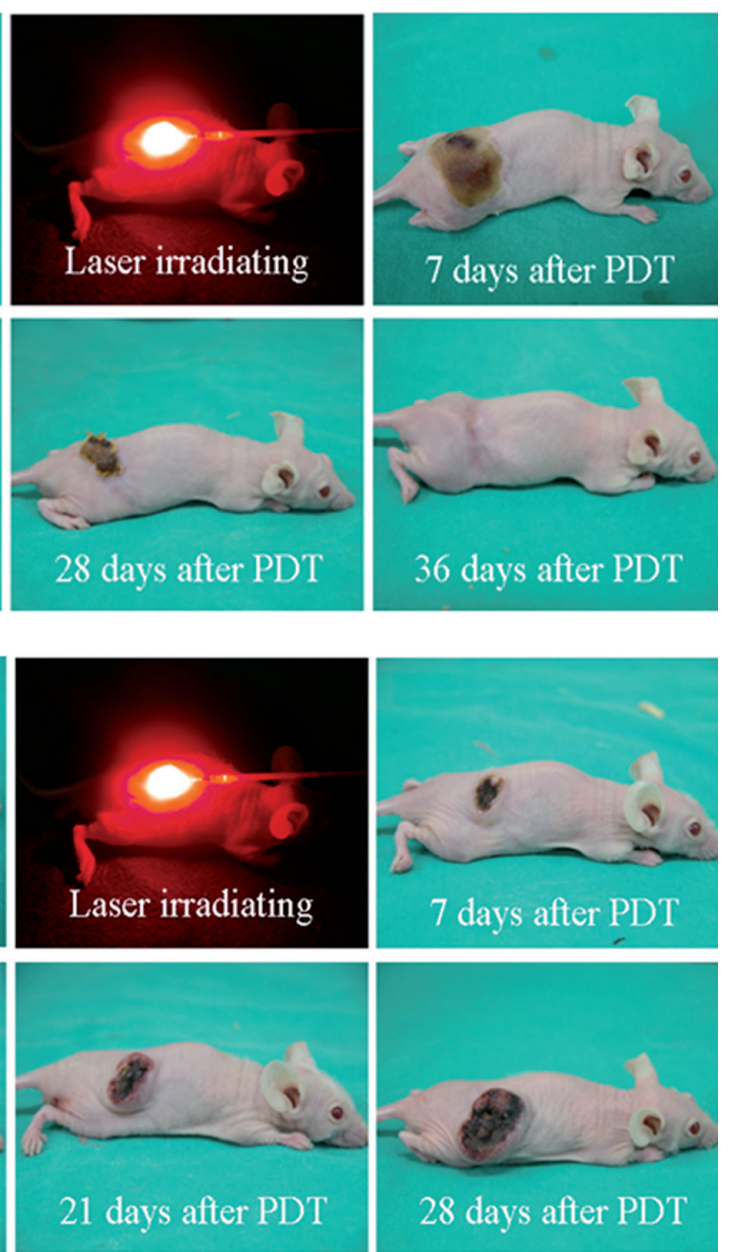
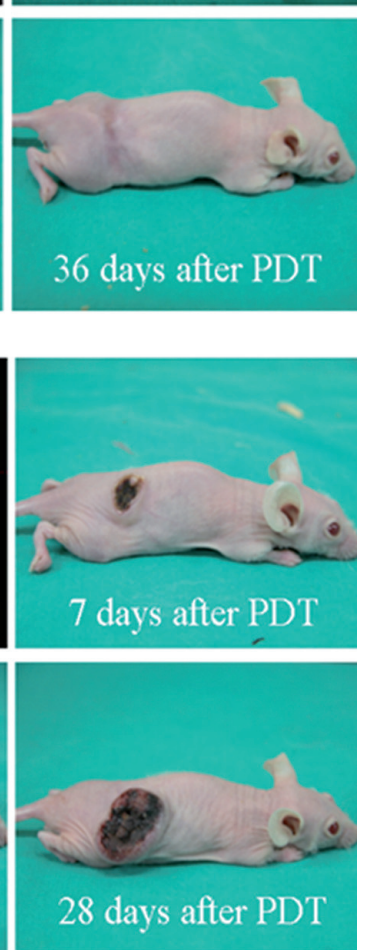

Figure 4. Effect of ALA-PDT+CDDP combination therapy on xenograft tumor of mice before and after 7, 14, 28, 36 days of laser irradiation. A. Photograph showing complete remission of tumors in combination treatment. Complete remission was observed in approximately $80 \%$ of cases. B. Photograph showing no remission of tumors. Approximately 7\% mice showed recurrence of tumors. 
other hand, $25 \mu \mathrm{g} / \mathrm{ml}$ and $50 \mu \mathrm{g} / \mathrm{ml}$ concentrations of ALA were selected for this combination treatment.

From the cell viability study, the percentages of cell viability were decreased when the cells were treated with $25 \mu \mathrm{g} / \mathrm{ml}$ and $50 \mu \mathrm{g} / \mathrm{ml}$ of ALA in PDT, respectively. Again, for CDDP at a concentration of $6.25 \mu \mathrm{g} / \mathrm{ml}$, the percentage of cell viability was approximately near the IC50 value compared to the control. But for the combination of CDDP with PDT at $25 \mu \mathrm{g} / \mathrm{ml}$ and $50 \mu \mathrm{g} / \mathrm{ml}$ of ALA, the cell viabilities were dramatically decreased. Therefore, the combination therapy was more effective than the monotherapy and showed higher effiacy even in the lower concentration of CDDP. Cell morphology was also changed in combination treatment. From microscopic study, it was found that the number of apoptotic cells with rounded shape was much higher compared to the control and even individual treatments.

For in vivo xenograph study, there was no significant difference in tumor size after 4 weeks of treatment with laser,

A

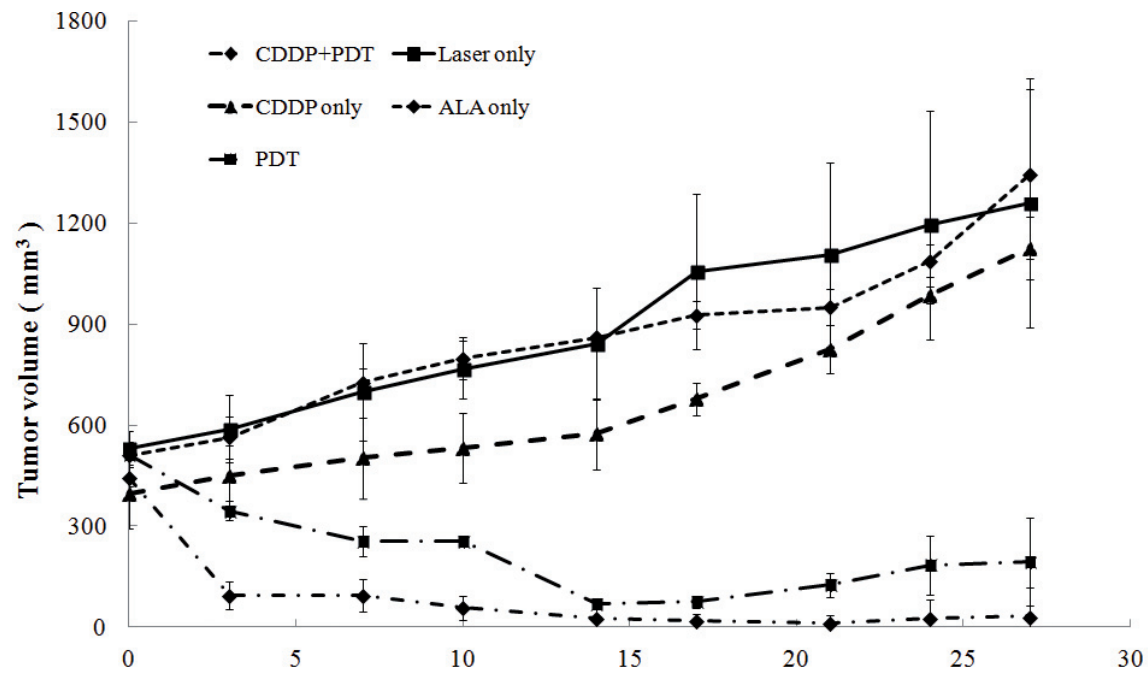

B

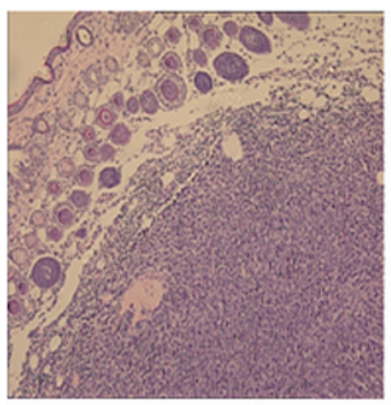

Control(X100)

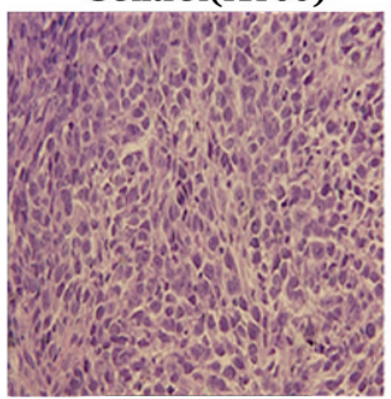

Control(X400)

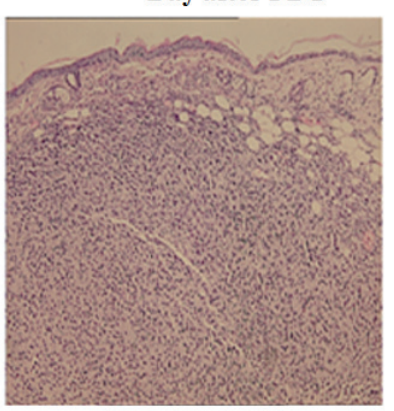

24h (X100)

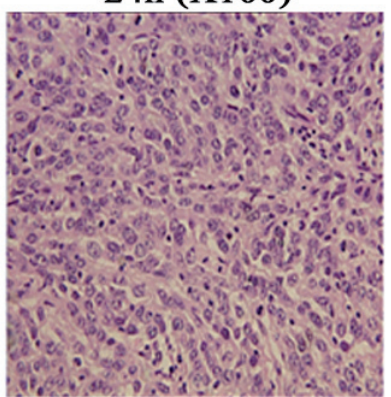

24h (X400)

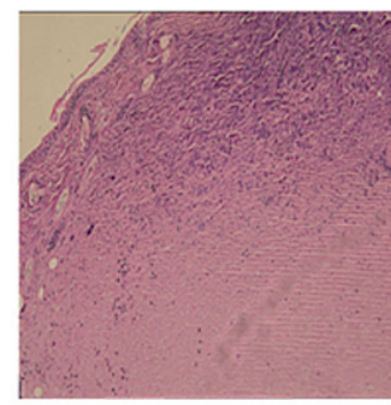

48h (X100)

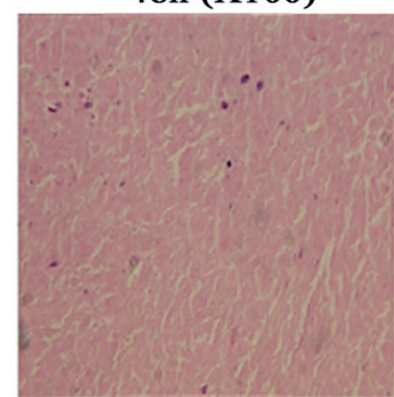

48h $(\mathrm{X} 400)$

Figure 5. A. Representative graph showing changes in tumor volume for each treatment group. B. Histologic findings of xenografted tumor after ALA-PDT+CDDP combination therapy. Tumors collected from the mice without any treatment i.e. neither CDDP nor ALAPDT served as a control group. After $24 \mathrm{~h}$ of ALA-PDT treatment, there were focal tumor necrosis and lymphocytic infiltration. Again after $48 \mathrm{~h}$ of ALA-PDT, there was extensive coagulative tumor necrosis. 
ALA and CDDP, respectively. But in the case of combination treatment with CDDP and ALA-PDT, significant decrease in tumor volume can be observed and recurrence of tumor was also significantly lower compared to the individual treatments. This result also signifies the enhance efficiency of combination therapy than the mono-therapy. Xenographed tumours were stained with Hematoxylin-eosin before the treatment, $24 \mathrm{~h}$ and $48 \mathrm{~h}$ after the treatment. From the microscopic study of the stained slides, necroses of the tumor and lymphocyte infiltration were observed in the tissue after $24 \mathrm{~h}$ of treatment and on the other hand, coagulative necrosis with inflammatory cells was observed around the tumor tissue after $48 \mathrm{~h}$ of treatment.

Therefore, the combination of ALA-PDT and CDDP has much more cytotoxic effect on AMC-HN3 cell than the effect of ALA-PDT and CDDP alone. Thus an enhanced effect can be obtained with the same concentrations of drugs applied individually. On the other hand, lower concentrations of CDDP as well as ALA can also be applied to achieve the same efficacy of individual treatments by combining two treatment modalities. Thus, the adverse side effects of CDDP can be reduced by reducing the concentration in combination therapy. Though more extensive studies are required, this mode of treatment can be an alternative treatment modality for reducing the side effects of cisplatin with a higher efficacy against head and neck cancer and other types of cancer.

Acknowledgements. The present research was conducted by the research fund from Institute of Bio-science and Technology at Dankook University in 2009.

The authors have no conflict of interest to declare.

\section{References}

Azmi A. S., Aboukameel A., Banerjee S., Wang Z., Mohammad M., Wu J., Wang S., Yang D., Philip P. A., Sarkar F. H., Mohammad R. M. (2010): Mdm2 inhibitor mi-319 in combination with cisplatin is an effective treatment for pancreatic cancer independent of p53 function. Eur. J. Canc. 46, 1122-1131 http://dx.doi.org/10.1016/j.ejca.2010.01.015

Bourré L., Giuntini F., Eggleston I. M., Wilson M., MacRobert A. J. (2008): 5-aminolaevulinic acid peptide prodrugs enhance photosensitization for photodynamic therapy. Mol. Cancer Ther. 7, 1720-1729 http://dx.doi.org/10.1158/1535-7163.MCT-08-0092

de Carvalho Maroni L., de Oliveira Silveira A. C., Leite E. A., Melo M. M., de Carvalho Ribeiro A. F., Cassali G. D., de Souza C. M., Souza-Fagundes E. M., Caldas I. R., Araujo M. S., MartinsFilho O. A., de Oliveira M. C., Teixeira-Carvalho A. (2012): Antitumor effectiveness and toxicity of cisplatin-loaded longcirculating and ph-sensitive liposomes against ehrlich ascitic tumor. Exp. Biol. Med. 237, 973-984 http://dx.doi.org/10.1258/ebm.2012.011432

Dougherty T. J., Gomer C. J., Henderson B. W., Jori G., Kessel D., Korbelik M., Moan J., Peng Q. (1998): Photodynamic therapy. J. Natl. Cancer Inst. 90, 889-905 http://dx.doi.org/10.1093/jnci/90.12.889

Ehrlich Y., Brames M. J., Beck S. D. W., Foster R. S., Einhorn L. H. (2010): Long-term follow-up of cisplatin combination chemotherapy in patients with disseminated nonseminomatous germ cell tumors: Is a postchemotherapy retroperitoneal lymph node dissection needed after complete remission? J. Clin. Oncol. 28, 531-536 http://dx.doi.org/10.1200/JCO.2009.23.0714

Florea A.-M., Büsselberg D. (2011): Cisplatin as an anti-tumor drug: Cellular mechanisms of activity, drug resistance and induced side effects. Cancers 3, 1351-1371 http://dx.doi.org/10.3390/cancers3011351

Geisler J. P., Swathirajan J., Wood K. L., Manahan K. J. (2012): Treatment of advanced or recurrent cervical cancer with cisplatin or cisplatin containing regimens: A cost effective analysis. J. Cancer 3, 454-458 http://dx.doi.org/10.7150/jca.4807

Go R. S., Adjei A. A. (1999): Review of the comparative pharmacology and clinical activity of cisplatin and carboplatin. J. Clin. Oncol. 17, 409

Gui T., Wang Y., Mao Y., Liu J., Sun S., Cao D., Yang J., Shen K. (2012): Comparisons of 5-aminolevulinic acid photodynamic therapy and after-loading radiotherapy in vivo in cervical cancer. Clin. Transl. Oncol. 2, 2

Heinemann I. U., Jahn M., Jahn D. (2008): The biochemistry of heme biosynthesis. Arch. Biochem. Biophys. 474, 238-251 http://dx.doi.org/10.1016/j.abb.2008.02.015

Henderson B. W. and Dougherty T. J. (1992): How does photodynamic therapy work? Photochem. Photobiol. 55, 145-157 http://dx.doi.org/10.1111/j.1751-1097.1992.tb04222.x

Karmakar S., Banik N. L., Patel S. J., Ray S. K. (2007): 5-aminolevulinic acid-based photodynamic therapy suppressed survival factors and activated proteases for apoptosis in human glioblastoma u87mg cells. Neurosci. Lett. 415, 242-247 http://dx.doi.org/10.1016/j.neulet.2007.01.071

Kennedy J. C., Pottier R. H., Pross D. C. (1990): Photodynamic therapy with endogenous protoporphyrin: Ix: Basic principles and present clinical experience. J. Photochem. Photobiol. B: Biology 6, 143-148

http://dx.doi.org/10.1016/1011-1344(90)85083-9

Kennedy J. C., Pottier R. H. (1992): New trends in photobiology: Endogenous protoporphyrin ix, a clinically useful photosensitizer for photodynamic therapy. J. Photochem. Photobiol. B: Biology 14, 275-292 http://dx.doi.org/10.1016/1011-1344(92)85108-7

Mao J., Zhang Y., Zhu J., Zhang C., Guo Z. (2009): Molecular combo of photodynamic therapeutic agent silicon(iv) phthalocyanine and anticancer drug cisplatin. Chem. Commun. 28, 908-910 http://dx.doi.org/10.1039/b817968a

Minami D., Takigawa N., Takeda H., Takata M., Ochi N., Ichihara E., Hisamoto A., Hotta K., Tanimoto M., Kiura K. (2012): Synergistic effect of olaparib with combination of cisplatin on pten deficient lung cancer cells. Mol. Cancer Res. 13, 13 
Okusaka T., Nakachi K., Fukutomi A., Mizuno N., Ohkawa S., Funakoshi A., Nagino M., Kondo S., Nagaoka S., Funai J., Koshiji M., Nambu Y., Furuse J., Miyazaki M., Nimura Y. (2010): Gemcitabine alone or in combination with cisplatin in patients with biliary tract cancer: A comparative multicentre study in japan. Br. J. Cancer 103, 469-474 http://dx.doi.org/10.1038/sj.bjc.6605779

Pujol-Lereis L. M., Massaldi A., Rabossi A., Quesada-Allué L. A. (2010): Photosensitizing effect of hematoporphyrin ix on immature stages of ceratitis capitata (diptera: Tephritidae). Photochem. Photobiol. 86, 639-644 http://dx.doi.org/10.1111/j.1751-1097.2009.00704.x

Ravi R., Somani S. M., Rybak L. P. (1995): Mechanism of cisplatin ototoxicity: Antioxidant system. BMC Pharmacol. Toxicol. 76, 386-394 http://dx.doi.org/10.1111/j.1600-0773.1995.tb00167.x

Regula J., MacRobert A. J., Gorchein A., Buonaccorsi G. A., Thorpe S. M., Spencer G. M., Hatfield A. R., Bown S. G. (1995): Photosensitisation and photodynamic therapy of oesophageal, duodenal, and colorectal tumours using 5 aminolaevulinic acid induced protoporphyrin ix--a pilot study. Gut 36, 67-75 http://dx.doi.org/10.1136/gut.36.1.67

Segawa Y., Kiura K., Takigawa N., Kamei H., Harita S., Hiraki S. Watanabe Y., Sugimoto K., Shibayama T., Yonei T., et al. (2010): Phase iii trial comparing docetaxel and cisplatin combination chemotherapy with mitomycin, vindesine, and cisplatin combination chemotherapy with concurrent thoracic radiotherapy in locally advanced non-small-cell lung cancer: Olcsg 0007. J. Clin. Oncol. 28, 3299-3306 http://dx.doi.org/10.1200/JCO.2009.24.7577

Sharman W. M., Allen C. M., van Lier J. E. (1999): Photodynamic therapeutics: Basic principles and clinical applications. Drug Discov. Today 4, 507-517 http://dx.doi.org/10.1016/S1359-6446(99)01412-9

Uehara M., Inokuchi T., Ikeda H. (2006): Enhanced susceptibility of mouse squamous cell carcinoma to photodynamic therapy combined with low-dose administration of cisplatin. J. Oral Maxillofac. Surg. 64, 390-396 http://dx.doi.org/10.1016/j.joms.2005.11.011

Yao X., Panichpisal K., Kurtzman N., Nugent K. (2007): Cisplatin nephrotoxicity: A review. Am. J. Med. Sci. 334, 115-124 http://dx.doi.org/10.1097/MAJ.0b013e31812dfele

Wolford S. T., Novicki D. L., Kelly B. (1995): Comparative skin phototoxicity in mice with two photosensitizing drugs: Benzoporphyrin derivative monoacid ring a and porfimer sodium (photofrin). Fundam. Appl. Toxicol. 24, 52-56 http://dx.doi.org/10.1006/faat.1995.1007

Zhang B., Ramesh G., Norbury C. C., Reeves W. B. (2007): Cisplatininduced nephrotoxicity is mediated by tumor necrosis factor-alpha produced by renal parenchymal cells. Kidney Int. 72, 37-44 http://dx.doi.org/10.1038/sj.ki.5002242

Received: December 20, 2012

Final version accepted: April 8, 2013 